\title{
Experiences of People who Acquire Motor Disability, in Adapting to Internal and Environment Changes
}

\author{
Karolina Matelionytė, Diana Karanauskienė \\ Lithuanian Sports University, Kaunas, Lithuania
}

\begin{abstract}
Background. In Lithuania, from 2017 to 2018, in the age group of 16-64 years, the number of people with a disability increased from $18.3 \%$ to $19.4 \%$ (Statistics on Persons with Disabilities, 2018). According to the 2014 European Statistical Data, as many as $27.1 \%$ of over 16 -year-olds with a disability in Europe reported prevailing limitations on their activity (Centre for European Social and Economic Policy, 2017). The significance of this current situation increases the relevance of this study, because insufficient attention is paid to disability research; researchers from around the world state that this area receives little of their attention (Rios et al., 2016; Shepherd, 2016; Williams \& Moore, 2011).

Methods. semi-structured interview, qualitative analysis of content.

Results. Negative reaction towards one's own body and the perceived irreversible physical changes after acquiring a disability provokes negative feelings, harmful behavior, and limits one's interaction with the environment. For those who acquire a disability, interaction with the environment encompasses difficulties in entering buildings, reaching for objects, moving outside or receiving certain services. When assessing communication with other people, after acquiring a disability, in many cases, communication with friends worsens, but becomes better with family and relatives. The process of overcoming the disability happens systematically - accepting the acquisition of disability and adapting to the changes that occur; taking up sports or communal activity in order to strengthen oneself physically, emotionally and engage in social life; expressing the inequalities prevalent in society regarding disability and the proposed possible ways to improve the situation.

Conclusion. People who acquire a disability encounter internal reactions and interaction with the changes in their environment, which create the strategic need to overcome the acquired disability and adapt to it.
\end{abstract}

Keywords: movement disability, acquired disability, internal changes, environment changes, experiences.

\section{INTRODUCTION}

$\mathrm{M}$ ovement disability encompasses limitation of the functions of one or both of a person's extremities, with lack of strength when walking, or holding or lifting objects. In the event of negatively impacted strength, speed, stamina, coordination, hand dexterity, disturbed movement amplitude, or control of extremities and mobility, the person may need appropriate aid in means and methods not only to improve their mobility, but also to overcome difficulties associated with skill learning (Colorado State University, 2020).

The United Nations Convention on the Rights of Persons with Disabilities (2006), which consolidates the rights of persons with disabilities, acknowledges that disability occurs due to the interaction of 
people with health disorders and obstacles posed by attitudes and environment. Such a process hinders thorough and effective participation in society on an equal level. Throughout the world, disabled people, as equal members of society, encounter obstacles in participating in society, and their human rights are infringed. In his article, Shepherd (2016) introduces current hindrances for the development of human rights and prevailing inequalities in social, education, employment and other areas; furthermore, due to the accessibility of services, people still encounter obstacles in taking up physical activity (de Hollander \& Proper, 2018). When reviewing the situation in Lithuania, the inequalities and obstacles encountered by disabled people are stated in the Alternative Report of Lithuanian Persons with Disability Forum Regarding the Implementation of the United Nations Convention on the Rights of Persons with Disabilities in Lithuania (2015).

Research object - internal and environment changes of people who acquire movement disability. The aim of the research was to analyze the experiences of people who acquire movement disability in adapting to internal and environment changes. Research objectives:

1. Determine what kind of internal changes do people who acquire movement disability encounter.

2. Determine what kind of interaction with environment changes do people who acquire movement disability encounter.

3. Analyze the most significant strategies for overcoming the internal and interaction with environment changes for people who acquire movement disability.

\section{METHODS}

Research participants. The subjects were selected by applying the non-probability theoretical target selection process. Selection criteria for informants: adults with acquired movement disability, who consented to participate in the research. The take of the research is nine informants. During the interview, the main demographic data of the subjects was uncovered, such essential social-demographic characteristics describing research participants: the age when the disability was acquired; for how many years the person has lived with disability; the type of acquired disability; and what work they do (Table 1). In order to ensure their confidentiality, the informants were encoded in capital alphabet letters. The age of subjects, based on when the disability was acquired, ranged from 14 to 42 years of age. Seven men and two women participated in the research. It became apparent that the movement disability, in majority of cases, was acquired through trauma suffered (damages to spinal cord when diving, road traffic accidents, accidents or amputation of a limb due to illness). When reviewing the work of the subjects, their fields of employment are extensive. Four research participants indicated that currently they do not work; others work as a taxi driver, museum employee, laboratory employee, or artist of leather articles. Eight participants indicated a close relation with sport after acquiring the disability and/or currently. Four research participants currently very actively take up sports (one of them is a professional).

Research methods. Qualitative research was performed. It gives depth to the review of the problem

Table 1. Sociodemographic data on informants

\begin{tabular}{|l|c|c|l|l|}
\hline \multicolumn{1}{|c|}{ Code } & $\begin{array}{c}\text { The age when } \\
\text { the disability } \\
\text { was acquired }\end{array}$ & $\begin{array}{c}\text { For how many years } \\
\text { the person is living } \\
\text { with disability }\end{array}$ & \multicolumn{1}{|c|}{$\begin{array}{c}\text { The type, cause of acquired } \\
\text { disability }\end{array}$} & Work \\
\hline Informant A & 27 & 10 & Traumatic spinal cord injury & Taxi driver \\
\hline Informant B & 19 & 11 & Traumatic spinal cord injury & $\begin{array}{l}\text { Currently does not work; creates poetry, } \\
\text { draws, prepares an article for publication }\end{array}$ \\
\hline Informant C & 20 & 11 & Traumatic spinal cord injury & Currently very actively take-up sports \\
\hline Informant D & 24 & 21 & Traumatic spinal cord injury & Currently does not work \\
\hline Informant E & 14 & 25 & Traumatic spinal cord injury & Employee of the museum \\
\hline Informant F & 42 & 36 & Traumatic spinal cord injury & Currently does not work \\
\hline Informant G & 17 & 14 & Traumatic spinal cord injury & Employee of the laboratory \\
\hline Informant H & - & 7 & Leg amputation & Artist of leather articles \\
\hline Informant I & 42 & & & \\
\hline
\end{tabular}


and allows to uncover its meaning. Such a method is necessary when researching the life aspects, behavior and interaction with other members of the communities of subjects. Qualitative research allows uncovering the peculiarities of social reality, the interaction of people participating therein and phenomena occurring therein. The researcher, who, while analyzing the source documents, expresses understanding about the object being researched and current situations, interprets the data and uncovers the experiences of the subjects; which is why the role of the researcher is significant (Poteliuniene, 2017; Žydziunaite \& Sabaliauskas, 2017).

For data gathering, a semi-structured interview method was selected, because it is a direct and primary method to gather the necessary information (to find out what the research participants think and know, and what is their point of view). It provides more possibilities to get to know and assess the subject in greater depth, it is a flexible survey method, the purpose of which is to receive information necessary for the goals of the research. This method allows commenting and explaining questions to the research participants, which they may not always understand (Kvale, 1996).

Research organization. The research was performed in the months of January and February 2021, after receiving permission from the Ethics Committee of Social Sciences of the Lithuanian Sports University to conduct the research. The informants were first contacted by phone. Having regard to the Lithuanian Republic Government requirements to control the spread of COVID-19 infection during quarantine, we agreed on a virtual meeting on an internet communications platform. Via e-mail, the forms of Informing the Subject and Consent of the Informed Person were forwarded to the informants. It was agreed that prior to the virtual meeting the informants would present the written consent to participate in the research by signing the Consent of the Informed Person form. The instrument used during the research was a structured questionnaire created by the author herself by following the analyzed scientific literature. The questionnaire was divided in to four question groups, names, which were oriented towards the purpose of the question, and what is meant to be uncovered with respective questions, were given to them. The first group of questions encompassed questions associated with contextual information in order to determine the age the subjects acquired the movement disability; its period; reason for it; and work activity. By the second group of questions "Familiarization with the Acquired Status of the Disabled Person" it was intended to find out how the subjects were informed about the disability; how they felt after knowing that it is permanent (Where and how did you get the most beneficial information about the disability?). With this group of questions, it was intended to uncover the methods used by the participants to gather strength and hope in order not to break down. The researcher wanted to know which subjects provided aid or recommendations after acquiring the disability and how was/is it being used (What kind of aid was provided to you (e.g., communication with the specialists at the health care institution/communication with the psychologist/the list of respective literature was given/contact information of persons with disabilities communities were given etc.)?). The third group of questions "The Changes of Social Role, Activities and Employment" encompassed questions associated with inequalities of physical environment and service provision currently being experienced/experienced right after acquiring the disability by the subjects. After determining the prevailing obstacles and obstacles that existed during the period of acquiring the disability, the researcher intended to find out what methods are chosen in order to adapt to the situation or change the usual day-to-day activity. Moreover, by this group of questions it was purposeful to uncover the peculiarities of the socialization process (How did you experience the isolation, separation from others process?; How did your role in the family change (father/mother, husband/wife, relations with people close to you)?). In order to determine the details of activities and employment of subjects, questions were given about the prevailing motivation to participate in social and physical activities and the current possibilities to take them up. This way, the researcher approached the questions regarding self-realization, goal achievement and disclosure of current difficulties of the subjects (How and in what areas you realize yourself?; How do you maintain your goals?; What difficulties you encounter when taking-up the activities?). By the fourth question group "Possible Changes in the Context of the Acquired Disability" it was intended to find out the thoughts of the subjects regarding the improvement of the situation of disability. The questions of this group were oriented towards uncovering the opinions and insights of research participants (Do 
you have any memorable instances from day-today activities associated with your adaptation to internal and environment changes after acquiring the disability?; If you had the possibility, what would you offer to change in the environment of persons with disability?; In your opinion, how it should be able to familiarize the persons, who acquired the movement disability, with physical and functional changes of the body, changes to the everyday, social or community activity?; In your opinion, what should be done in order to increase the positive view of the society towards disability?). The questionnaire comprised 33 questions. The questions to the informants were given in the same order. In order to achieve an in-depth analysis, during interview, additional questions were given.

Questioned informants - people who acquired a movement disability. Interview with each informant lasted 30 - 90 minutes. After informants gave their consent, a sound recorder was used. Transcript records of conversation with each informant were prepared - Informant Records. In order to determine the smooth course and clarity of the interview, additional questions were given to research participants. The research was performed remotely, having coordinated with the subjects the time of conversation and assuring in regards to the communication means at hand (platforms Zoom and Messenger). During the interview, an internet camera was used in order to monitor emotions, behavior and expression of the informants when answering questions. These emotions helped in understanding the experiences of research participants.

In order to preserve human rights, ensure autonomy and safety of research participants, during research, principles laid down in the Universal Declaration on Bioethics and Human Rights (2005) and Helsinki Declaration (1975), and ethic goodwill, autonomy, awareness, confidentiality, justice and privacy assurance principles were followed (Zydziunaite, 2011; Gerikiene et al., 2015).

Data analysis. The research data were analyzed using the qualitative analysis method of the subject matter, because it creates conditions to perform in-depth data analysis. Qualitative analysis of the subject matter creates conditions for analyzing the thoughts expressed by the subjects, for having regard to their feelings and emotions and for uncovering the experiences of them (Zydziunaite, 2011).

The synthesizing of deduction data method was applied when analyzing data - the statements received during semi-structured interview were equated to purposeful units, divided in to subcategories and categories. Categories match the keywords-notions of given questions. The summaries of statements given by informants (answers to questions) become sub-categories. This way, the peculiarities of familiarization with disability, ways to overcome negative thoughts and feelings, inequalities of interaction with environment, advantages of taking up societal and sports activity and the expression of society's view towards disability are disclosed.

\section{RESULTS}

Expression of Internal Changes. When analyzing the received results, it is seen that adaptation to the internal changes after acquiring the disability in most cases is associated with the acceptance of disability and is two-fold - negative and positive.

Due to the negative reaction towards their own body and environment (" $<\ldots$.. $>$ we cannot take care of ourself, <...> neither go to the toilet, nor take a bath, $<\ldots>$ we even cannot leave our home, because there is no appropriate infrastructure <...> [I]), many subjects experienced psychological crisis (" $<\ldots>$ this is a very big trauma - psychological trauma <...>." $[\mathrm{HJ}]$ ). The latter began having bad habits, separated herself from others, started not to trust herself, and was prone to loneliness and depression. However, after reviewing the thoughts of subjects, it appears that after the expression of negative feelings towards disability subjects shift to positive thoughts when the hope to be able to walk again prevails (" $<\ldots>$ there were some thoughts that I will walk for a bit <...>." [E]), even persistent striving for it. As time goes by, subjects accept the disability. The subjects expressed the acceptance with physical and functional changes of the body, as well as, psychological adaptation to the environment.

Changes in Relation to the Environment. Difficulties of accessing buildings are highlighted: the major obstacle are stairs. Subjects encounter them in public spaces and at home, because the household is not equipped in accordance with the needs of the person with disability. Public service provision places, especially toilets, receive a lot of complaints regarding unsuitability. The shortfalls in the infrastructure are highlighted, they do not only create short-term inconveniences when it becomes 
difficult or impossible to access one place from another, but they also increase the risk of trauma (" $<\ldots$..> one time I fell out of my wheelchair, because I did not notice a small hole on the pedestrian walkway." $[D])$. When reviewing the changes in the service sphere, the subjects encounter the need to independently inquire about the receipt of service. This encompasses the upfront booking of service via phone or on the internet, when having explained the situation to the service providers they agree to service the person outside near the respective institution or at the person's home.

The significance of helpers or organizational help is highlighted in order not only to overcome the obstacles of physical environment when entering premises, but also when receiving respective services: $<\ldots>$ in some way $<\ldots>$ I'm certainly not against $<\ldots>$ for someone helping me. $<\ldots>$ as a last resort, someone brings me up, <...> I do not uphold the view, that $<\ldots>$ as some say "I'm not a cupboard, I will not allow myself to be lifted up, because independently" $<\ldots .>$. $<\ldots>$ you can show your principle and rob yourself $<\ldots>$, because you will not receive that service at all." [B]. Such thoughts of the subjects allow the understanding that even though the need for a helper or help is expressed when aiding access to certain places, the feeling of independence and autonomy is very important: "In order to be able to do this yourself $<_{\ldots} .>$ and it does not matter $<_{\ldots} . .>$ whether that place has accessibility problems, or problems with other people, but the gist is, you should have to do it yourself." [E].

It is a known fact that the process of socialization for people with an acquired disability is important. However, a clear worsening of this process after acquiring the disability is monitored. In many cases, the subjects indicated that their friends distanced from them, which is why communication greatly diminished. Whereas, relations with family members remained unchanged or even became better (" $<\ldots>$ relatives, friends, co-workers $<\ldots$, , of course, they are the cheering team." [F]).

When reviewing the socialization process from the point of view of society, and by following the thoughts of the informants, it can be seen that favorable and non-favorable points of view towards disability prevail in society. Even though bystanders sometimes offer their help, in some cases, a confrontational mood emerges when asking for help, showing a reluctance to accept someone with a disability within the community.
Such manifestation of a negative view may develop due to thoughtless decisions of the government, or improper actions. Due to this negative perception of disability, the subjects do not always feel safe and comfortable around able-bodied people: " $<\ldots$..> I would not really go alone to a sports club where only healthy people go, because <...> people keep staring at you and they do not understand what is wrong with me, why I'm so peculiar. $<$...> I wouldn't feel comfortable, because $<\ldots>$ not everyone understands what this disability is and $<\ldots>$ why am I like that." $[\mathrm{H}]$ ). Whereas, when reviewing the manifestations of the favorable point of view, it is seen that it is more prevalent among younger people. A supposition can be made that it is due to the broader understanding about disability and the current historical context when the disability is not kept secret as if it were not to exist.

The Most Significant Strategies for Overcoming Internal and Relation with Environment Changes. With the development of internal changes, and those in relation to the environment, people with an acquired movement disability need to understand the significance of overcoming such changes and to foresee the possible ways of overcoming negative phenomena. First of all, the processes that happen during the acquisition of a disability are reviewed (Table 2).

The usefulness of information mostly becomes apparent when other people with disabilities share their experience: " $<\ldots$..> many other people having the same lot as me, the circle expanded; more information, more proposals, more activities and everything unravels quickly." [D] Communication with other people with disabilities provides comprehensive benefits - not only is the disability familiarized more broadly, people include themselves in common activities, become a fully-fledged part of the community, but they also feel safer ("Maybe psychologically is easier near people similar to me." $[\mathrm{H}]$ ). People within disability organizations are a splendid example of such developing communities. Whereas, prior to becoming acquainted with other people with disabilities, there was a prominent lack of information about the disability or familiarization with it. When asked about the familiarization with the disability, provision of useful information, pointing out contact information of communities or respective literature in the health care institutions, a couple of subjects stated that such things were not even mentioned in passing. 
Table 2. The Acceptance of the Fact of Disability and Strategies for Overcoming It

\begin{tabular}{|c|c|c|}
\hline \multirow{3}{*}{ 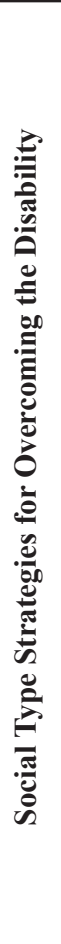 } & $\begin{array}{l}\text { Support from } \\
\text { the closest } \\
\text { people }\end{array}$ & 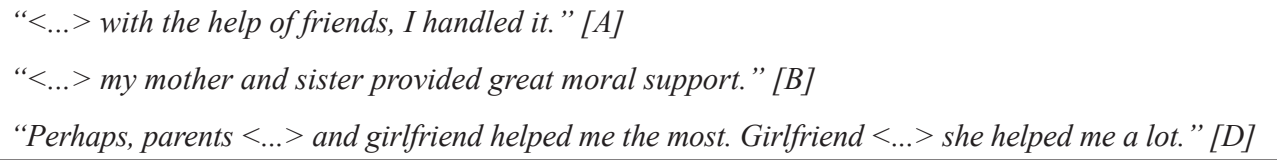 \\
\hline & $\begin{array}{l}\text { Activity of } \\
\text { rehabilitation } \\
\text { institutions }\end{array}$ & 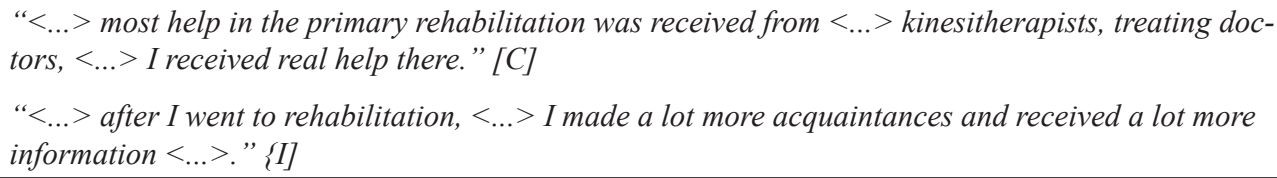 \\
\hline & $\begin{array}{l}\text { Activity of } \\
\text { persons with } \\
\text { disability } \\
\text { organizations }\end{array}$ & 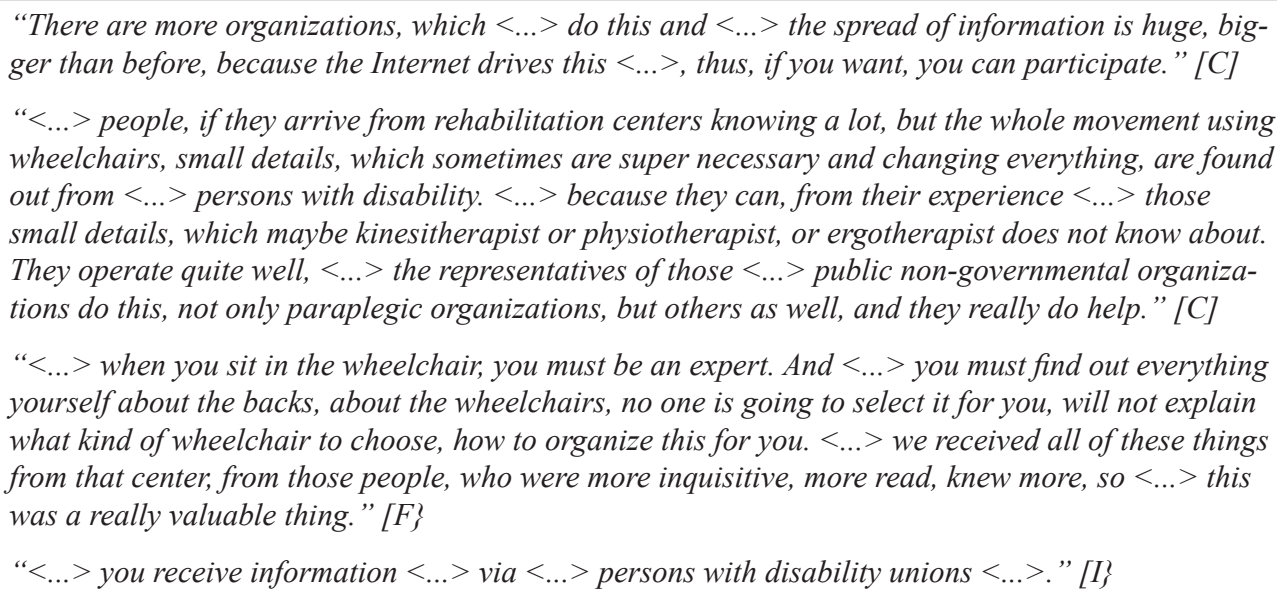 \\
\hline 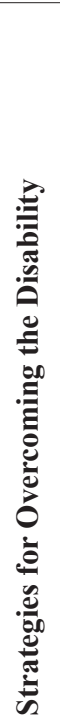 & $\begin{array}{l}\text { Searching for } \\
\text { information } \\
\text { about } \\
\text { disability }\end{array}$ & 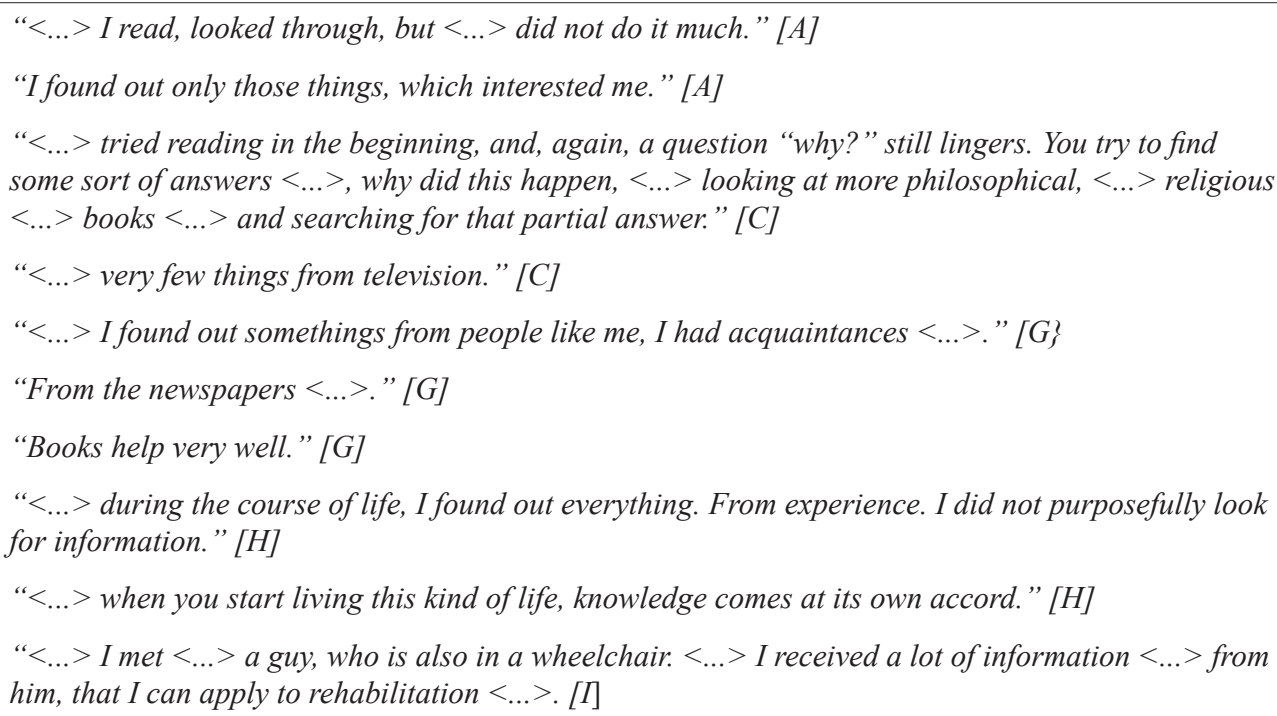 \\
\hline 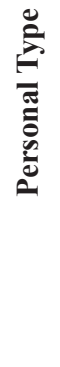 & $\begin{array}{l}\text { Personal } \\
\text { endeavors }\end{array}$ & $\begin{array}{l}\text { "<... }>\text { I had to try myself, because, if they will see that you are abusing your condition and do not do } \\
\text { anything at all, then you will not gather your support team." }[\mathrm{F}] \\
\text { "You have to be a busy bee, later on, when your friends come, you can for an hour smile, but you } \\
\text { have to so much invest in yourself, that }<\ldots>\text { there is no time to be sad or wheeze." [F] } \\
\text { "Strength comes from somewhere... Belief also adds to this. You still hope that you will stand up". [G] } \\
\text { "You add, strategize, plan }<\ldots>\text { to make things easier }<\ldots . .>\text { to avoid any inconveniences, troubles, } \\
\text { you do not go where it is slippery. }<\ldots>\text { in order not to get yourself in trouble, because there will not } \\
\text { be many to help you." [H] }\end{array}$ \\
\hline
\end{tabular}

When accepting the acquired status of the person with disability, the importance of support from those people closest to them, and rehabilitation specialists, is highlighted. According to the informants, support and familiarization with the process of acquiring the disability is most actively performed in rehabilitation institutions. However, this is not always direct - it is not the information, which is directly presented by the specialists, but, while being among other people with disability, a person independently finds out various relevant things. 
Significant stages of familiarization with the disability are distinguished - the assimilation of theoretical knowledge and learning of practical skills.

It is significant to mention that, after the psychological crisis which occurs after the acquisition of disability, it is proposed to provide information or re-familiarize with it after a certain period of time, having regard to the psychological condition of the person ("Alas, sometimes <...> people, during that thankless period when rejection reaction occurs, often do not hear the information. Maybe, at later stages, when $<\ldots>$ his is more prone, passes through $<\ldots>$ those denials, <...> periods for assimilating the disability, maybe the same information said to him, repeated to him has more meaning than before." [C]).

Comprehensive strengthening of the person who acquired the disability is inseparable from engaging in physical and social activities. The selection of activities is decisive in order to more actively adapt to the changed environment by becoming physically fitter and more easily overcoming physical obstacles in the environment and participating in social activities, and in order to broaden one's horizons.

When the research participants expressed their opinion on the given questions, the peculiarities of society's view towards disability were disclosed. This view was two-fold - favorable and nonfavorable. In the event of the non-favorable view, following the thoughts of the subjects, the necessity to take up respective actions became apparent in order to achieve a development of more favorable point of view of society towards persons with disability. As is seen from analyzing the research results, the latter actions should encompass the changing of people's point of view, and various ways of overcoming the changes which people with acquired disability encounter, in various aspects.

In order to increase society's positive point of view towards disability, the subjects propose to shape the understanding of disability from an early age. An alternative method is using the press to present society with positive examples about people with disabilities, depicting a positive picture of someone with a disability ("<...> we need to show good practices how people <...> live, what they are capable of." [E]; "<...> point of view of people that not all persons with disability are poor souls and victims. This is perhaps the main thing." $[D])$. In order to create not only a more favorable view, but also conditions to adapt in society and personal space, the necessity to apply the household in accordance with the Program for Applying the Household to Persons with Disability is expressed. Furthermore, the importance of providing information to the person is mentioned (" $<\ldots$.. $>$ in the hospital, they should get all of documentation on all questions $<\ldots .>$. It should mention where to get psychological help, social services and how does the compensatory mechanism work." [F]). A closer interaction with one's environment would be shaped this way for the person with the disability; from the moment of acquiring it, conditions would occur to feel less excluded from society. The role of state policy in increasing the positive point of view towards disability and shaping favorable living conditions for people with disabilities is highlighted. Resentment is expressed that the politicians do not do enough regarding people with disabilities. However, when reviewing all of the thoughts expressed by the informants, one of the ways to improve others' perception of people with disabilities becomes apparent - the need to change the behavior of the people with disabilities themselves. It can be seen that people with disabilities express negative emotions and do not always communicate pleasantly with those wanting to help. Which is why it is highlighted that it is purposeful for members of society to communicate and cooperate in order to achieve the best results: "This is mutual work from the side of society, <...> person with disability and organizations. That this must $<\ldots>$ be $<_{\text {... }}>$ symbiosis, everyone must be closely associated and $<\ldots>$ not only scream, demand and say that everything is bad, bad... $<\ldots>$ ' $[C]$.

\section{DISCUSSION}

When performing this research, it was intended to research the experiences of people with acquired disabilities in adapting to internal and environment changes. In order to determine what kind of internal changes such people encounter, negative and positive acceptance of disability methods were discovered. The received results highlighted the negative initial reaction of subjects towards their physically and physiologically changed body, and understanding about cardinal changes of activity and lifestyle after acquiring the disability. However, as time goes on, disability is accepted by using respective means, as discussed below. 
The research results disclosed that changes occur in physical environment, service area and socialization process. Poor accessibility of buildings, problems of reaching objects, services not adapted, and lack of skills for training people with disabilities create these obstacles (Bragaru et al., 2013, Phoenix et al., 2015). When assessing the changes that occur in public and home spaces, the subjects highlighted issues of entering buildings where the stairs become the main obstacle. Furthermore, thoughtless placement of objects and items pose hindrances as well, because it is hard to reach the item you want, or to use the toilet. Moreover, when reviewing the environment in a broader sense, potholed pedestrian walkways, high kerbs or improperly installed access ways are obstacles posing a lot of hindrances. All of these obstacles indicated by the subjects are closely related to the receipt of services. In the event of physical and environment inequalities, it is more complicated to receive the service, as was mentioned, if the access to the building or to an object is impeded. It is important to understand the significance of communicating with others when assessing the relation with the environment, because the process of socialization is inseparable from the interaction of person and environment. People with disabilities experience considerable social isolation (Orsmond et al., 2013) and difficulties in creating significant relationships (Shapiro \& Martin, 2014). A supposition can be made that in the absence of sturdy enough social connection, the acquisition of disability causes damage, which was brought to light when summarizing the thoughts expressed by the research participants highlighting the prevalent perception of society towards people with disabilities.

When performing the research, it was important to fathom the strategies regarding internal and relation with environment changes. The disclosure of such strategies is significant for the expression of negative emotions experienced by people after acquiring a disability. Those who acquired a movement disability highlight the activity of people within disability organizations when receiving the necessary information right after the acquisition of disability, and after taking opportunities to participate in various activities, communicate, and become fully-fledged members of the community - not only of the community of people with disabilities, but of society as a whole. Even though the physical functions of a person with an acquired movement disability change, after reviewing the literature and comparing the thoughts of the authors with the performed research, it is purposeful to highlight that participation in organized sports and recreation activities has a lot of benefit for physical readiness (Dahan-Oliel et al., 2012), socialization skills (Shapiro, Martin, 2014; McConkey et al., 2012) and general wellbeing (Dahan-Oliel et al., 2012). Based on the research results, it appears that sport is important when adapting to internal and environment changes after acquiring the disability, however, the intensity of taken-up sports activity is not significant. Physical activity of people with a disability, irrespective of its type, provides comprehensive benefit. In such a way, not only is wellbeing created for a person with disability, but a more favorable point of view towards disability is shaped in society. The subjects actively expressed the importance of such a need. Not only is the need of favorable opinion towards disability stressed, but also the creation of a positive relation with one's environment. As the research results showed, these processes should encompass the education of society, publication of good examples in the topic of disability, adaptation of the physical environment, changing of activity of service providers and assuring of favorable conditions. Which is why, in summary, it can be stated that people who acquire a movement disability could more easily adapt to changes after acquiring the disability if various subjects would be included in to this process. As stated in the summary of the World Report on Disability (Disability and Working Capacity Assessment Office under the Ministry of Social Security and Labor of the LR, 2014), the government, UN agencies and development organizations, disabilities organizations, service providers, education institutions, private sector, communities, people with disabilities themselves and their families should be responsible for the improvement of the life of those with disabilities. Moreover, when increasing the attractiveness to take up physical activity, which is very useful, it is important to train trainers, instructors and staff working with people with disabilities in order for them to help in meeting different needs in accordance to the level of recipients' capabilities (Horne \& Spring, 2014). However, even though physical activity is significant, it does not always help to adapt to changes created by a disability, because there is a lack of favorable participation conditions (Whitall, 2015) and means, which 
reflects after analyzing the thoughts of the subjects. Which is why the variety of activities and accessibility of objects has more importance. This means that the accessibility of activity places, sports clubs, stadiums, inventory, locker rooms and other obligatory objects must be ensured (Horne \& Spring, 2014). It should be stated that, while proposals, recommendations and guidelines on how to decrease the exclusion of people with acquired movement disability and internal barriers have been provided, their implementation is as yet inadequate. Which is why the understanding of changes that have occurred, and individual expression and impact on the performance of day-to-day activities, are significant, and require attention to be paid to the conditions and needs of those who acquired a disability.

\section{CONCLUSIONS}

1. People who acquire a movement disability initially negatively accept it. Negative reaction towards one's own body and the perceived irreversible physical and physiological changes after acquiring the disability provoke negative feelings, harmful behavior and limiting oneself from the environment. The remaining probability of walking again creates two-fold feelings - negative, when the status of a person with disability is yet to be understood, and supporting and strengthening feelings, which, as time goes by, become sturdier and help to accept the acquired disability.
2. The interaction between people with an acquired movement disability and their environment encompasses changes of both physical environment and social communication. Changes in public and home environment become evident (difficulties of entering buildings, reaching for objects, moving outside), and receiving certain services. The stated property in relation to environment is important - having the intention, despite adversity in the environment, to remain as far as possible independent and not become a burden to others. When assessing the communication with other people, after acquiring the disability, in many cases, the communication with friends worsens, but becomes better with family and relatives.

3. With respect to changes, both internal and regarding their environment, people who acquire a movement disability need to understand the significance of overcoming such changes, and foresee the possible ways of overcoming negative phenomena. The process for dealing with a disability happens systematically - accepting the acquisition of disability and adapting to the changes that occur; taking up sports or communal activity in order to strengthen oneself physically, emotionally and to engage in social life; expressing the inequalities prevalent in society regarding disability, and the proposed possible ways to better the situation.

\section{REFERENCES}

Bragaru, M., van Wilgen, C.P., Geertzen, J.H.B., Ruijs, S.G.J.B., Dijkstra, P.U., \& Dekker, R. (2013). Barriers and facilitators of participation in sports: a qualitative study on Dutch individuals with lower limb amputation. PLoS ONE, 8, 1-9. doi: https://doi. org/10.1371/journal.pone.0059881

Centre for European Social and Economic Policy (2017). European comparative data on Europe 2020 \& People with disabilities. Retrieved from https://www.disabilityeurope.net/theme/statistical-indicators

Colorado State University (2020). Department of Occupational Therapy. Module: Mobility Impairments. Retrieved from http://accessproject.colostate.edu/ disability/modules/MI/tut_MI.php?display=pg_1

Dahan-Oliel, N., Shikako-Thomas, K., \& Manjnemer, A. (2012). Quality of life and leisure participation in children with neurodevelopmental disabilities: a thematic analysis of the literature. Quality of Life Research, 21, 427-439. doi: https://doi.org/10.1007/s11136-011-0063-9

de Hollander, E.L, \& Proper, K.I. (2018). Physical activity levels of adults with various physical disabilities. Preventive Medicine Reports, 10, 370-376. doi: https:// doi.org/10.1016/j.pmedr.2018.04.017

Francis, J.J., Johnston, M., Robertson, C., Glidewell, L., Entwistle, V., Eccles, M.P., \& Grimshaw, J.M. (2010). What is an adequate sample size? Operationalising data saturation for theory-based interview studies. Psychology and Health, 25, 1229-1245. doi: https://doi. org/10.1080/08870440903194015

Gerikiene, V., Gudinavicius, B., Lescinskienè, L., Mockeviciene, E., \& Sakalauskiene, A. (2015). Methodological requirements for the preparation and defense of the final work. Siauliai: Siauliai State College. Horne, B., \& Spring, E. (2014). Motivate me: 
Understanding what motivates and appeals to disabled people to take part in sport and physical activity. Retrieved from http://www.activityalliance.org.uk/howwe-help/research/1874-motivate-me-may-2014.

United Nations (2006). Convention on the Rights of Persons with Disabilities and Optional Protocol. Retrieved from https://e-seimas.lrs.lt/portal/legalAct/lt/ TAD/TAIS.335882

Kvale, S. (1996). Interviews: An Introduction to Qualitative Research Interviewing. Sage, Thousand Oaks.

Lithuanian Disability Forum (2015). Alternative report on the implementation of the United Nations Convention on the Rights of Persons with Disabilities in Lithuania. Retrieved from http://www.negalia.lt/wp-content/ uploads/2016/02/JT-Neigaliuju-teisiu-konvencijosAlternatyvioji-ataskaita.pdf

Matelionyte, K. (2020). Experiences of persons, who acquired movement disability, in adapting to internal and environment changes. Sport Forum - International Scientific Conference Athlete Training Management and Determinants of Sports Performance (p. 49-50). Kaunas: Lithuanian Sport University.

McConkey, R., Dowling, S., Hassan, D., \& Menke, S. (2013). Promoting social inclusion through unified sports for youth with intellectual disabilities: a five-nation study. Journal of Intellectual Disability Research, 57, 923-935. doi: https://doi.org/10.1111/j.1365-2788.2012.01587.x

Moore, A.M., Claphamb, E.D., \& Deeneya, T.A. (2018). Parents' perspectives on surf therapy for children with disabilities. International Journal of Disability, Development and Education, 65, 304-317. doi: https:// doi.org/10.1080/1034912X.2017.1400660

Disability and Working Capacity Assessment Office under the Ministry of Social Security and Labor of the LR (2014). The summary of the World Report on Disability. Retrieved from https://apps.who.int/iris/bitstream/ handle/10665/70670/WHO NMH VIP 11.01 lit.pdf;js essionid $=\mathrm{C} 1 \mathrm{~F} 49 \mathrm{E} 22 \mathrm{~F} 11 \mathrm{D} 10640041 \mathrm{BA} 8 \mathrm{ED} 66 \mathrm{BD} 6 \mathrm{C} ? \mathrm{~s}$ equence $=64$

Orsmond, G.I., Shattuck, P.T., Cooper, B.P., Sterzing, P. R., \& Anderson, K.A. (2013). Social participation among young adults with an autism spectrum disorder. Journal of Autism and Developmental Disorders, 43, 2710-2719. doi:10.1007/s10803-013-1833-8.

World Medical Association (1975). Declaration of Helsinki. On the ethical principles of medical research involving patients. Retrieved from https://www.esavadai. lt/dokumentai/1496-helsinkio-deklaracija/

Phoenix, C., Griffin, M., \& Smith, B. (2015). Physical activity among older people with sight loss: a qualitative research study to inform policy and practice. Public health, 129, 124-130. doi: https://doi.org/10.1016/j. puhe.2014.10.001

Poteliuniene, S. (2017). Review of Vilma Zydziunaite and Stanislav Sabaliauskas' textbook 'Qualitative Research: Principles and Methods". Sports Science, 1, 69-71. doi: https://doi.org/10.15823/sm.2017.11

Rios, D., Magasi, S., Novak, C., \& Harniss, M. (2016). Conducting accessible research: including people with disabilities in public health, epidemiological, and outcomes studies. AJPH, 106, 2137-2144. doi: https:// doi.org/10.2105/AJPH.2016.303448

Shapiro, D.R., \& Martin, J.J.M. (2014). The relationships among sport self-perceptions and social well-being in athletes with physical disabilities. Disability and Health Journal, 7, 42-48. doi: https://doi.org/10.1016/j. dhjo.2013.06.002

Shepherd, J. (2016): Purpose, process and future direction of disability research. Disability \& Society, 31, 1-3. doi: https://doi.org/10.1080/09687599.2016.1141576

Statistics on Persons with Disablities (2018). Master tables concerning EU 2020: year 2018. Retrieved from https://www.disability-europe.net/theme/statisticalindicators.

Universal Declaration on Bioethics and Human Rights (2005). Retrieved from http://bioetika.sam.lt/index. php?880317146

Whitall, J. (2015). Physical activity alone may enhance health but it may not reduce disability in chronic stroke survivors. Kinesiology Review, 4, 3-10. doi: https://doi. org/10.1123/kr.2014-0072

Williams, A.S., \& Moore, S.M. (2011). Universal design of research: inclusion of persons with disabilities in mainstream biomedical studies. Science Translational Medicine, 3, 1-10. doi: https://doi.org/10.1126/ scitranslmed.3002133

Zydziunaite, V. (2011). Thesis preparation methodology: textbook. Retrieved from http://www.esparama.lt/es parama pletra/failai/ESFproduktai/2012 Baigiamojo darbo_metodologija.pdf

Zydziunaite, V., \& Sabaliauskas, S. (2017). Qualitative Research: Principles and Methods: A Textbook for Social Science Students. Vilnius: Vaga. 